\title{
Comparative Expression Profiling of Lactogenic Hormone Receptor and It's Signaling Molecules of Bovine Mammary Glands during lactation
}

\author{
Shinichi Yonekura1,2,3*, Honami Miyazaki², Yukako Tokutake ${ }^{3}$ \\ ${ }^{1}$ Department of Interdisciplinary Genome Sciences and Cell Metabolism, Institute for Biomedical Sciences, \\ Interdisciplinary Cluster for Cutting Edge Research (ICCER), Shinshu University, Minami-minowa, Nagano, Japan \\ ${ }^{2}$ Graduate School of Agriculture, Shinshu University, Minami-minowa, Nagano, Japan \\ ${ }^{3}$ Interdisciplinary Graduate School of Science and Technology, Shinshu University, Minami-minowa, Nagano, \\ Japan \\ Email: ${ }^{*}$ yonekura@shinshu-u.ac.jp
}

Received 9 March 2015; accepted 27 March 2015; published 31 March 2015

Copyright (C) 2015 by authors and Scientific Research Publishing Inc.

This work is licensed under the Creative Commons Attribution International License (CC BY). http://creativecommons.org/licenses/by/4.0/

(c) (i) Open Access

\begin{abstract}
Milk synthesis is known to be modulated by peptide hormones such as prolactin (PRL), growth hormone (GH), and insulin-like growth factor I (IGF-I). Previous studies suggested that PRL and IGF-I acted directly on mammary epithelial cells and were involved in lactation. Meanwhile, GH is thought to be indirectly involved in lactation by stimulating the secretion of IGF-I. It is controversial as growth hormone receptors (GHR) is expressed in the mammary epithelial cells. In order to clarify whether GH acted directly on mammary gland tissue, we investigated the prolactin receptors (PRLR), IGF-I receptors (IGF-IR), and GHR as well as the gene expression levels of the downstream signaling molecule for each receptor in the mammary gland tissue of Holstein cows during different stages of lactation. The results revealed that the mRNA expressions of PRLR and IGF-IR were highest during early lactation, and the mRNA expression of the GHR was highest during midlactation. We also found that the expression profiling of the signal transducer and activator of transcription 5 (STAT5) genes was similar to that of the GHR gene. On the other hand, the expression profiling of the PRLR gene was similar to that of the SHP2 gene. These results suggest that GH acts on the mammary glands directly, milk synthesis and secretion are chiefly stimulated in mid-lactation, and the timing of the action is different for PRL and IGF-I.
\end{abstract}

\footnotetext{
Corresponding author.
}

How to cite this paper: Yonekura, S., Miyazaki, H. and Tokutake, Y. (2015) Comparative Expression Profiling of Lactogenic Hormone Receptor and It's Signaling Molecules of Bovine Mammary Glands during lactation. Open Journal of Animal Sciences, 5, 106-113. http://dx.doi.org/10.4236/ojas.2015.52013 


\section{Keywords}

\section{Lactation, Growth Hormone, Prolactin, Signal Transduction, Mammary Gland}

\section{Introduction}

The development of mammary gland begins from the development of the mammary duct system from sexual maturity into mid-pregnancy. The mammary alveolus is formed from mid-pregnancy, the development of the mammary glands is almost completed in late pregnancy, and the mammary epithelial cells of the mammary alveolus begin to produce real milk postpartum. However, an involution of the mammary glands occurs with the decrease in mammary alveolus cell formation in latter lactation, causing milk yield to decrease remarkably. Mammary gland development in the period from pregnancy to lactation is caused by the interaction between the hormones and the growth factors. It is known that milk synthesis is modulated by peptide hormones such as prolactin (PRL), growth hormone (GH), and insulin-like growth factor I (IGF-I) [1].

PRL is widely known to play a key role in the development and differentiation of mammary gland based on the results of research on rodents. PRL acts directly on the differentiation and maintenance of secretory cells through the prolactin receptors (PRLR) in mammary epithelial cells [2]. Previous reports suggested that IGF-I also acted directly in the mammary epithelial cells, and was involved in the proliferation and differentiation of breast epithelial cells [3]. On the other hand, it is thought that GH is indirectly involved in milk lactation by stimulating the secretion of IGF-I [4] [5]. However, it had been reported that hormone receptors (GHR) was expressed in the mammary epithelial cells [6] and that GH could directly modulate casein and leptin gene expression in the mammary epithelial cells [7]. As it has been reported that administration of recombinant bovine GH to lactating dairy cow increases milk yield [8], it is very important to clarify the action mechanism of GH during lactation.

The downstream of PRLR, IGF-I receptors (IGF-IR), and GHR was involved in common signal transduction molecules, such as Janus kinase 2 (JAK2), signal transducer and activator of transcription 5 (STAT5), Src homology 2 domain-containing transforming protein C (SHC), and insulin receptor substrate 1 (IRS-1). Previous study indicated that PRL transmitted through JAK2/STAT5 [9] and, in particular, that PRL was involved in the transcription of $\beta$-casein through STAT5 [10]-[12]. Among three receptors, Src homology 2 domain containing protein-tyrosine phosphatase (SHP2) is known as a downstream signaling molecule of PRLR. Previous studies indicated that SHP2 was activated by prolactin and took part in the transcription of $\beta$-casein genes [13]. Though STAT1 and STAT3 are reported as downstream signaling molecules of GHR among three receptors [14], it is not clear whether the activation of these signal molecules is involved in milk synthesis.

Therefore, in order to clarify whether GH acted directly on mammary gland tissue, we investigated the mRNA expression of PRLR, IGF-IR, and GHR as well as that of the downstream signaling molecule for each receptor in the mammary gland of Holstein cows during different stages of lactation.

\section{Materials and Methods}

\subsection{Animals, Tissue Sampling and Preparation}

The mammary gland from Holstein cow $(\mathrm{n}=12)$ was removed within 20 min after slaughter during defined stages. Small pieces $(1-2 \mathrm{~g})$ of mammary glands was frozen in liquid nitrogen and stored at $-80^{\circ} \mathrm{C}$. The classification of the animals was established as follows: 1) Early lactation stage (day $6-18$ of lactation, $n=3$ ); 2) Middle lactation stage (day $124-158$ of lactation, $\mathrm{n}=3$ ); 3) Late lactation stage (day $276-306$ of lactation, $\mathrm{n}=$ $3)$; 4) Dry period ( 1 month after the beginning of dry period, $n=3)$. The treatment of the animals was according to "Guiding Principles for the Care and Use of Animals in the Field of Physiological Sciences" (The Physiological Society of Japan).

\subsection{RNA Extraction}

Total RNA was isolated from mammary glands using the TRIzol reagent (Life Technologies), according to the manufacturer's instructions. The concentration of the isolated total RNA was determined by measuring the optical density at $260 \mathrm{~nm}$, and the purity of the RNA was determined based on the ratio of the absorbance at $260 \mathrm{~nm}$ 
relative to the absorbance at $280 \mathrm{~nm}$.

\subsection{End-Point RT-PCR}

Two micrograms of RNA were then processed for cDNA synthesis using a ReverTra Ace RT Master Mix (TOYOBO, Japan). Conditions for the enzymatic amplification were optimised for all the factors studied. For every PCR amplification, the linear range was verified by introducing increasing cDNA amounts as well as cycle numbers. PCR was performed using the EX Taq DNA Polymerase (TAKARA, Japan). Amplification conditions included 30 (PRLR, GHR, STAT3, SHC and IRS-1), 33 (STAT5, STAT1 and SHP2), 35 cycles (IGF-1R and JAK2) of denaturation at $94^{\circ} \mathrm{C}$ for $1 \mathrm{~min}$, annealing at $55^{\circ} \mathrm{C}\left(60^{\circ} \mathrm{C} \mathrm{JAK} 2\right.$ and SHC) for $1 \mathrm{~min}$. A single denaturation step at $94^{\circ} \mathrm{C}$ for $2 \mathrm{~min}$ and a final extension step at $72^{\circ} \mathrm{C}$ for 2 min were performed, except for GAPDH: 19 cycles of denaturation at $94^{\circ} \mathrm{C}$ for $45 \mathrm{~s}$, annealing at $55^{\circ} \mathrm{C}$ for $45 \mathrm{~s}$ and extension at $72^{\circ} \mathrm{C} 45 \mathrm{~s}$. The primer sequences are shown in Table 1. GAPDH was used as an endogenous control. The PCR products were separated in a $2 \%$ agarose gel, stained with ethidium bromide, and analyzed using Fluor-S Multilmager (Bio-Rad, Hercules, CA). The intensity of leptin abundance was assigned as a ratio to that of GAPDH abundance. The sequences of all PCR products were verified by sequencing.

\subsection{Statistical Analysis}

In all of the experiments, the values are expressed as the means \pm standard error of the mean, with at least 3 replicates in each experimental group. Statistical significance was determined by a one-way ANOVA followed by the Turkey-Kramer analysis. The test was considered significant if $P<0.05$.

\begin{tabular}{|c|c|c|}
\hline Gene & Accession number & Primers (5' to $\left.3^{\prime}\right)$ \\
\hline \multirow{2}{*}{ PRLR } & \multirow{2}{*}{ NM_174155.3 } & Forward CCATCCTTTCTGCTGTCAT \\
\hline & & Reverse CTTGCTCCGTGTGTTCTTT \\
\hline \multirow{2}{*}{ GHR } & \multirow{2}{*}{ NM_176608.1 } & Forward ACCCAGTGGAAAATGGACCCTT \\
\hline & & Reverse CTGTCTGTGTCTGACCCTTCAGTC \\
\hline \multirow{2}{*}{ IGF-IR } & \multirow{2}{*}{ NM_001244612.1 } & Forward TTAAAATGGCCAGAACCTGAG \\
\hline & & Reverse ATTATAACCAAGCCTCCCAC \\
\hline \multirow{2}{*}{ JAK2 } & \multirow{2}{*}{ DT897449 } & Forward TTGGCAATGACAAACAAGGA \\
\hline & & Reverse ATCTCATCTGGGCATCCATC \\
\hline \multirow{2}{*}{ STAT5 } & \multirow{2}{*}{ NM_001012673 } & Forward TGCATCCGCCATATTCTGTA \\
\hline & & Reverse AGTCGCAGCTCCTCAAATGT \\
\hline \multirow{2}{*}{ SHC } & \multirow{2}{*}{ NM_001164061.1 } & Forward GTGAGGTCTGGGGAGAAGC \\
\hline & & Reverse GGTTCGGACAAAGGATCACC \\
\hline \multirow{2}{*}{ IRS-1 } & \multirow{2}{*}{ XM_003585773.3 } & Forward CATGCACGAGACAATCCTGG \\
\hline & & Reverse CCTGTTGGTGCTAGGACTC \\
\hline \multirow{2}{*}{ SHP2 } & \multirow{2}{*}{ NM_174742.2 } & Forward CGGTCTGGCAATACCACTTT \\
\hline & & Reverse TCGTGTCCTTTCCTCTTGCT \\
\hline \multirow{2}{*}{ STAT3 } & \multirow{2}{*}{ NM_001012671.2 } & Forward CAACCCCAAGAACGTGAACT \\
\hline & & Reverse GAAGGTACCTGGGGGCTTAG \\
\hline \multirow{2}{*}{ STAT1 } & \multirow{2}{*}{ XM_003583326.2 } & Forward AGCAAGCGTAACCTTCAGGA \\
\hline & & Reverse CATTCTTTGCCACACCATTG \\
\hline \multirow{2}{*}{ GAPDH } & \multirow{2}{*}{ NM_001034034.1 } & Forward TGACCCCTTCATTGACCTTC \\
\hline & & Reverse GTCTTCTGGGTGGCAGTGAT \\
\hline
\end{tabular}




\section{Results}

\subsection{The mRNA Expression of Lactogenic Hormone Receptor in Mammary Glands during Lactation}

We extracted RNA from the mammary gland of Holstein cows at varying lactation periods (early lactation, middle lactation, and late lactation) and dry periods. Then we analyzed the mRNA expression of PRLR, IGF-IR, and GHR using end-point RT-PCR. The expression of PRLR and IGF-IR were the highest in early lactation and it decreases significantly after mid-lactation (Figure 1). On the other hand, however, GHR gene expression increases from early lactation until mid-lactation, and then significantly decreases in late lactation (Figure 1).
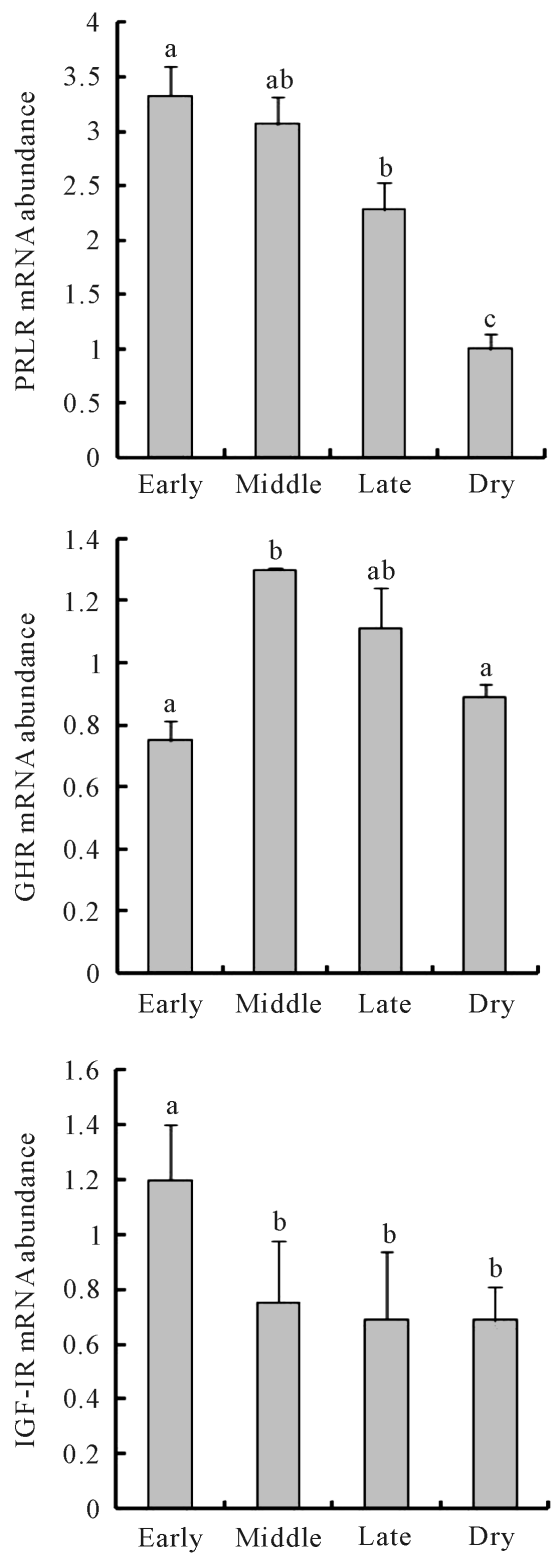

Figure 1. PRLR, GHR and IGF-1R expression in mammary glands during lactation. Mammary glands were collected from early lactation stage (Early), middle lactation stage (Middle), late lactation stage (Late) and dry period Holstein cows. And then total RNA was isolated and subjected to end-point RT-PCR analysis. Each mRNA abundance assigned as a ratio to GAPDH mRNA abundance. The Results are shown as the \pm S.E.M $(n=3)$. Points with a different superscript are significantly different $(P<0.05)$. 


\subsection{The mRNA Expression of JAK2, STAT5, SHC and IRS-1mRNA in Mammary Glands during Lactation}

We then analyzed the mRNA expression of JAK2, STAT5, SHC, and IRS-1 that are shared as PRLR, IGF-IR, and GHR downstream signaling molecules. We found that the expression of JAK2, STAT5, and SHC genes significantly increased from early to mid-lactation, and significantly decreased after late lactation (Figure 2). IRS-1 gene exhibited the highest expression in early lactation, and it decreases significantly after late lactation.

\subsection{The Expression of SHP2, STAT3, and STAT1 mRNA in Mammary Glands during Lactation}

Finally, we analyzed the mRNA expression of SHP2, which is only found downstream of the PRLR among three receptors; and we examined STAT3 and STAT1 mRNA expression, the signal molecules that exist only downstream of the GHR. The expression of STAT3 was increased from early lactation through mid-lactation, and then significantly decreased during non-lactation (Figure 3). We did not observe any significant changes in the expression of the STAT1 gene during lactation.

\section{Discussion}

The expression level of the GHR gene significantly increased from early lactation through mid-lactation and significantly decreased from late lactation onward. The result of the change in GHR gene expression level by lactation period suggests that GH directly acts on the mammary glands. In addition, based on the result that the
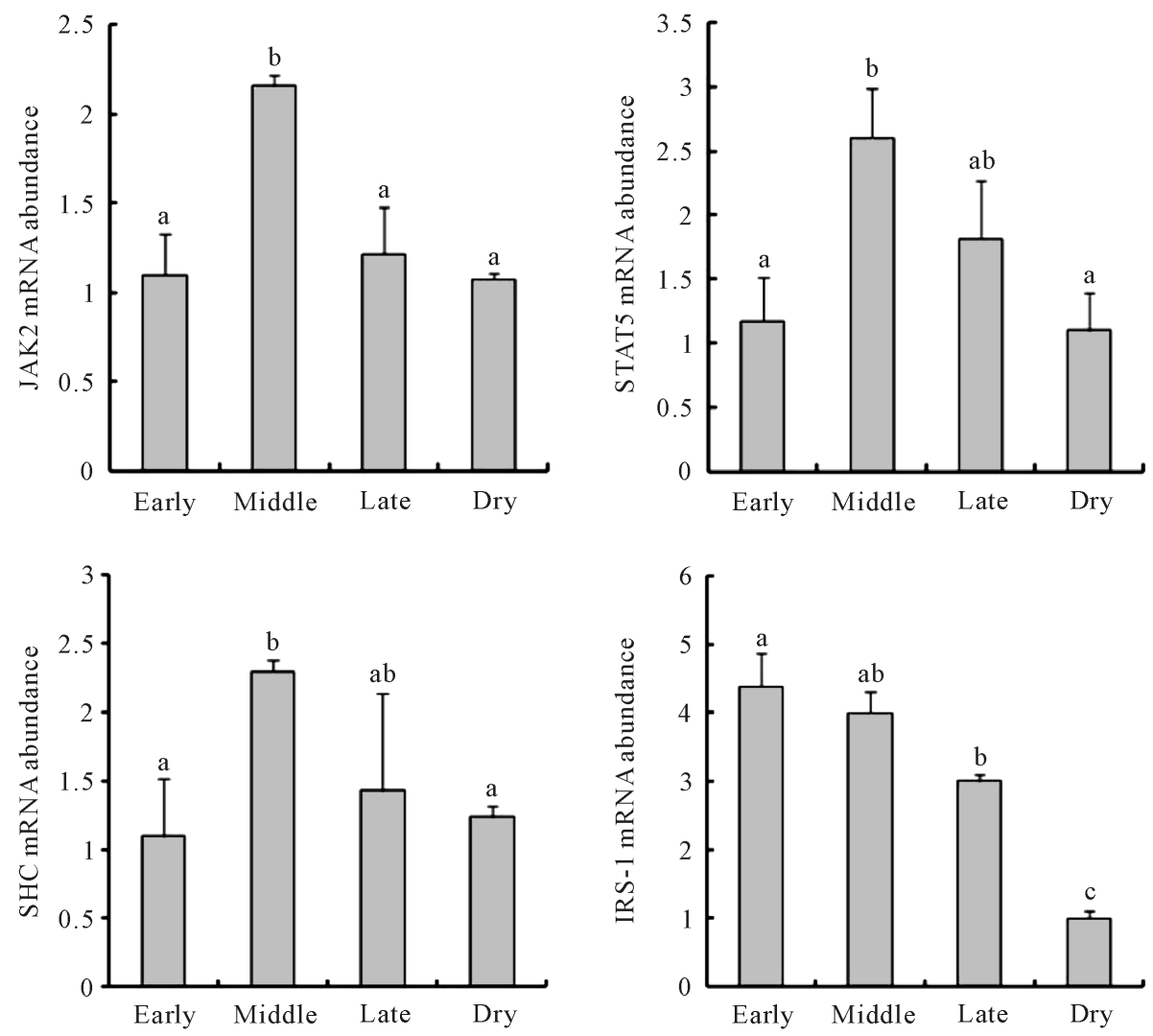

Figure 2. JAK2, STAT5, SHC and IRS-1 expression in mammary glands during lactation. Mammary glands were collected from early lactation stage (Early), middle lactation stage (Middle), late lactation stage (Late) and dry period Holstein cows. And then total RNA was isolated and subjected to end-point RT-PCR analysis. Each mRNA abundance assigned as a ratio to GAPDH mRNA abundance. The Results are shown as the \pm S.E.M $(n=3)$. Points with a different superscript are significantly different $(P<0.05)$. 

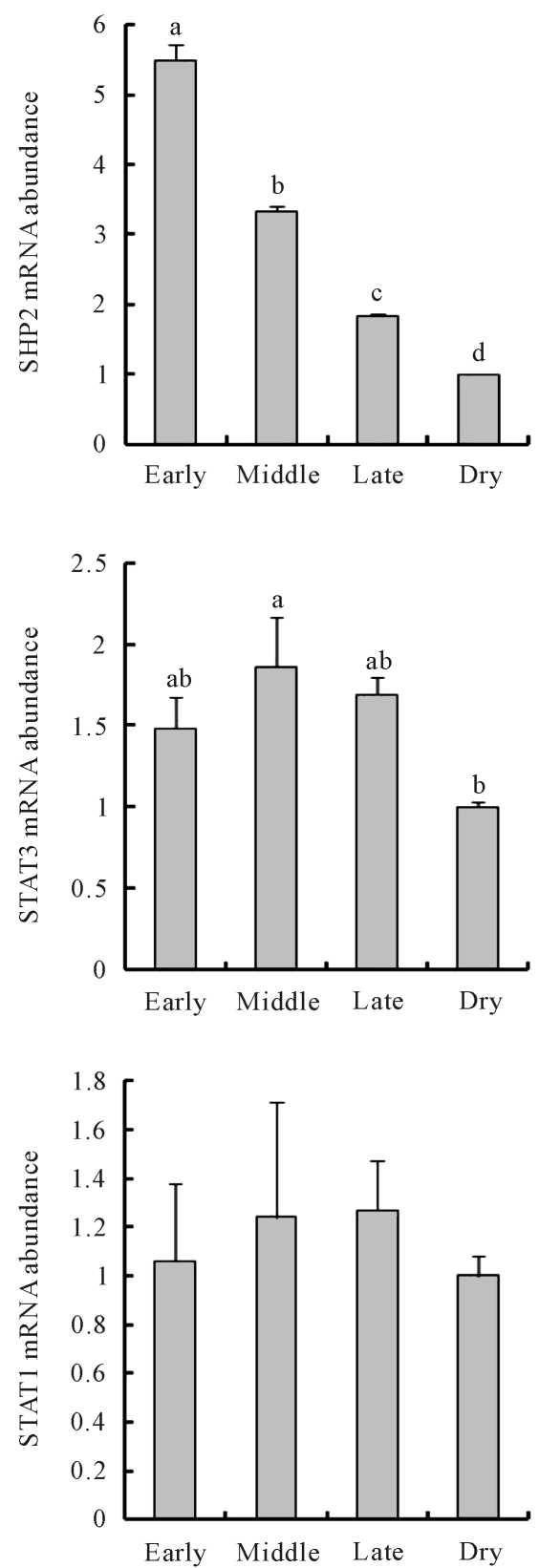

\begin{abstract}
Figure 3. SHP2, STAT3 and STAT1 expression in mammary glands during lactation. Mammary glands were collected from early lactation stage (Early), middle lactation stage (Middle), late lactation stage (Late) and dry period Holstein cows. And then total RNA was isolated and subjected to end-point RT-PCR analysis. Each mRNA abundance assigned as a ratio to GAPDH mRNA abundance. The Results are shown as the \pm S.E.M $(n=3)$. Points with a different superscript are significantly different $(P<0.05)$.
\end{abstract}

PRLR gene and the IGF-IR gene expression levels were highest in early lactation while the GHR gene expression level was highest in the early lactation, it can be assumed that the action time for GH differs from that of PRL and IGF-I.

The expression level of the JAK2 and STAT5 genes significantly increased from early lactation through midlactation and significantly decreased after late lactation. The expression profiling of these genes was similar to the expression profiling of the GHR. This result implies that GH enhances the activity of JAK2/STAT5 signals in mammary gland. It has been reported that PRL acts directly on the mammary glands and promotes the tran- 
scription of the $\beta$-casein gene through JAK2/STAT5 pathway [10]. However, the expression profiling of the JAK2 and STAT5 were different from those of the PRLR. These results indicate that PRL promotes the $\beta$-casein synthesis through JAK2 and STAT5 in early lactation and mid-lactation, and that JAK2/STAT5 signals are increasing due to participation by GH in mid-lactation. The expression profiling of SHC was also similar to that of GHR. This result implies that GH enhances the SHC signal in mammary gland. The role of the SHC signals (including PRL and IGF-I) in milk synthesis, however, has remained unknown, so further research is required.

The mRNA expression level of SPH2 was highest in early lactation and decreased significantly in mid-lactation. SHP2 gene expression profiling was found to be similar to PRLR gene one. This result is consistent with previous reports indicating that SHP2 was activated by PRL and was involved in the synthesis $\beta$-casein [13]. In addition, as the milk yield was highest during early lactation, we speculate that SHP2 pathway by PRL through in early lactation has greater influence on milk production than the pathway through JAK2/STAT5. STAT3 gene expression profiling resembles GHR and JAK2 gene expression profiling, which suggests that JAK2/STAT3 pathways are activated by GH in the mammary gland. Although previous study reported that the activation of STAT3 by GHs in rat livers [14], there has been no reports of this in mammary tissue. Subsequent research is necessary to investigate whether the activation of JAK2/STAT3 pathways by GH in mammary tissue influences milk synthesis.

\section{Conclusion}

In conclusion, our data suggest that GH acts on the mammary gland directly, and that milk synthesis and secretion are chiefly stimulated in mid-lactation. It is known that milk production in dairy cows is generally highest in early lactation before decreasing thereafter. Although our results suggest that PRL has a higher lactation effect than $\mathrm{GH}$, but we posit that $\mathrm{GH}$ also acts directly on the mammary gland and has lactation effects.

\section{Acknowledgements}

This study was supported in part by a Kieikai Foundation award to Dr. S. Yonekura.

\section{References}

[1] Neville, M.C., McFadden, T.B. and Forsyth, I. (2002) Hormonal Regulation of Mammary Differentiation and Milk Secretion. Jounal of Mammary Gland Biology and Neoplasia, 7, 49-66. http://dx.doi.org/10.1023/A:1015770423167

[2] Bachelot, A. and Binart, N. (2007) Reproductive Role of Prolactin. Reproduction, 133, 361-369. http://dx.doi.org/10.1530/REP-06-0299

[3] Khandwala, H.M., McCutcheon, I. E., Flyvbjerg, A. and Friend, K.E. (2000) The Effects of Insulin-Like Growth Factors on Tumorigenesis and Neoplastic Growth. Endocrine Reviews, 21, 215-244. http://dx.doi.org/10.1210/edrv.21.3.0399

[4] Kleinberg, D.L., Ruan, W., Catanese, V., Newman, C. B. and Feldman, M. (1990) Non-Lactogenic Effects of Growth Hormone on Growth and Insulin-Like Growth Factor-I Messenger Ribonucleic Acid of Rat Mammary Gland. Endocrinology, 126, 3274-3276. http://dx.doi.org/10.1210/endo-126-6-3274

[5] Shushanov, S.S. (2011) Insulin-Like Growth Factors 1 and 2 Regulate Expression of Beta-Casein in Vitro in Mouse Mammary Epithelial Cells. Bulletin of Experimental Biology and Medicine, 152, 202-205. http://dx.doi.org/10.1007/s10517-011-1488-4

[6] Katoh, K., Komatsu, T., Yonekura, S., Ishiwata, H., Hagino, A. and Obara, Y. (2001) Effects of Adenosine 5'-Triphosphate and Growth Hormone on Cellular H+ Transport and Calcium Ion Concentrations in Cloned Bovine Mammary Epithelial Cells. Journal of Endocrinology, 169, 381-388. http://dx.doi.org/10.1677/joe.0.1690381

[7] Yonekura, S., Sakamoto, K., Komatsu, T., Hagino, A., Katoh, K. and Obara, Y. (2006) Growth Hormone and Lactogenic Hormones Can Reduce the Leptin mRNA Expression in Bovine Mammary Epithelial Cells. Domestic Animal Endocrinology, 31, 88-96. http://dx.doi.org/10.1016/i.domaniend.2005.09.002

[8] Bauman, D.E., Eppard, P.J., DeGeeter, M.J. and Lanza, G.M. (1985) Responses of High-Producing Dairy Cows to Long-Term Treatment with Pituitary Somatotropin and Recombinant Somatotropin. Journal of Dairy Science, 68, 1352-1362. http://dx.doi.org/10.3168/jds.S0022-0302(85)80972-3

[9] Leonard, W.J. and O’Shea, J.J. (1998) Jaks and STATs: Biological Implications. Annual Review of Immunology, 16, 293-322. http://dx.doi.org/10.1146/annurev.immunol.16.1.293

[10] Schmitt-Ney, M., Doppler, W., Ball, R.K. and Groner, B. (1991) Beta-Casein Gene Promoter Activity Is Regulated by 
the Hormone-Mediated Relief of Transcriptional Repression and a Mammary-Gland-Specific Nuclear Factor. Molecular and Cellular Biology, 11, 3745-3755.

[11] Gouilleux, F., Wakao, H., Mundt, M. and Groner, B. (1994) Prolactin Induces Phosphorylation of Tyr694 of Stat5 (MGF), a Prerequisite for DNA Binding and Induction of Transcription. EMBO Jounal, 13, 4361-4369.

[12] Darvin, P., Joung, Y.H. and Yang, Y.M. (2013) JAK2-STAT5B Pathway and Osteoblast Differentiation. JAKSTAT, 2, e24931. http://dx.doi.org/10.4161/jkst.24931

[13] Ali, S., Chen, Z., Lebrun, J.J., Vogel, W., Kharitonenkov, A., Kelly, P.A. and Ullrich, A. (1996) PTP1D Is a Positive Regulator of the Prolactin Signal Leading to beta-Casein Promoter Activation. EMBO Journal, 15, 135-142.

[14] Ram, P.A., Park, S.H., Choi, H.K. and Waxman, D.J. (1996) Growth Hormone Activation of Stat 1, Stat 3, and Stat 5 in Rat Liver. Differential Kinetics of Hormone Desensitization and Growth Hormone Stimulation of Both Tyrosine Phosphorylation and Serine/Threonine Phosphorylation. Journal of Biological Chemistry, 271, 5929-5940. http://dx.doi.org/10.1074/jbc.271.10.5929 